\title{
4
}

\section{Quality of Life in Dilated Cardiomyopathy with Refractory Chronic Heart Failure Undergoing Devices Implantation}

\author{
Elisabete Nave Leal ${ }^{1}$, José Luís Pais Ribeiro ${ }^{2}$ and Mário Martins Oliveira ${ }^{3}$ \\ ${ }_{1}^{1}$ Polytechnic Institute of Lisbon/School of Health Technology of Lisbon \\ ${ }^{2}$ University of Porto/Faculty of Psychology and Educational Sciences \\ ${ }^{3}$ Lisbon Central Hospital Center, Santa Marta Hospital \\ Portugal
}

\section{Introduction}

Heart failure is the final stage of most of cardiac diseases. It is a complex syndrome in which the patients should have the following features: symptoms of heart failure, typically shortness of breath at rest or during exertion, and/or fatigue; signs of fluid retention such as pulmonary congestion or ankle swelling; and objective evidence of an abnormality of the structure or function of the heart at rest. This progressive syndrome as a high incidence and prevalence and poor prognosis: four-year mortality is around $50 \%$ with $40 \%$ of the patients admitted to hospital dying or readmitted within a year (European Society of Cardiology, 2008). With ageing, many patients will develop chronic heart failure, which, because of its symptoms, patient's awareness of their risk of dying, and the effects of therapy, together with frequent hospitalizations, has considerable impact on patient's health-related quality of life.

In the actual field of management, implantable devices have an important role for select patients. According to the European Society of Cardiology guidelines for the diagnosis and treatment of acute and chronic heart failure (2008), cardiac resynchronization therapy with defibrillator function is recommended to reduce morbidity and mortality in patients in New York Heart Association III-IV class who are symptomatic despite optimal medical therapy, and who have a reduced ejection fraction (left ventricular ejection fraction $\leq 35 \%$ ) and QRS prolongation (QRS width $\geq 120 \mathrm{~ms}$ ) and implantable cardioverter-defibrillator is recommended for primary prevention of sudden death to reduce mortality in patients with ventricular dysfunction due to prior myocardial infarction or non-ischemic cardiomyopathy with a left ventricular ejection fraction $\leq 35 \%$ in New York Heart Association functional class II or III, receiving optimal medical therapy, and who have reasonable expectation of survival with good functional status for more than one year.

The effect of these therapies in the quality of life in general and regarding the type of therapeutic response in particular is a field under investigation.

The aim of this study was to evaluate the impact of cardiac resynchronization therapy and implantable cardioverter-defibrillator in the quality of life of patients with chronic heart failure refractory to optimal pharmacological therapy in the first six months after device implantation. 


\section{Method}

\subsection{Participants}

From ninety-six patients with chronic heart failure refractory to optimal pharmacological therapy in consecutive sequential analysis, fifty-two underwent implantation of cardiac resynchronization therapy system combined with implantable cardioverter-defibrillator and forty-four systems with implantable cardioverter-defibrillator alone for primary prevention of sudden death.

In the cardiac resynchronization therapy group, age was $64,2 \pm 8,9$ (37-78) years with 35 males and 17 females, left ventricular ejection fraction was $24,6 \pm 5,4(11-35) \%$ and $94 \%$ in class III of the New York Heart Association classification. The etiology was mostly idiopathic $(46,2 \%)$ or ischemic $(34,6 \%)$.

In the implantable cardioverter-defibrillator group, age was $61,1 \pm 12,6(25-83)$ years with 38 males and 6 females, left ventricular ejection fraction was 26,1 $\pm 5,4(15-37) \%$ and $82,9 \%$ in class II of New York Heart Association classification. The etiology was mostly ischemic (75\%) (Figure 1).

\begin{tabular}{|c|c|c|c|}
\hline & Characteristics & $\begin{array}{c}\text { Cardiac } \\
\text { Resyncrhronization } \\
\text { Therapy } \\
\end{array}$ & $\begin{array}{l}\text { Implantable } \\
\text { Cardioverter- } \\
\text { Defibrillator } \\
\end{array}$ \\
\hline \multirow[t]{2}{*}{ Age } & $\underline{\mathrm{M}}$ & 64,2 & 61,1 \\
\hline & $\underline{\mathrm{DP}}$ & 8,9 & 12,6 \\
\hline \multirow[t]{2}{*}{ Gender } & Male & $67,3 \%$ & $86,4 \%$ \\
\hline & Female & $32,7 \%$ & $13,6 \%$ \\
\hline \multirow{2}{*}{$\begin{array}{l}\text { Left Ventricular } \\
\text { Ejection Fraction }\end{array}$} & $\underline{\mathrm{M}}$ & $24,6 \%$ & $26,1 \%$ \\
\hline & $\underline{\mathrm{DP}}$ & 5,4 & 5,4 \\
\hline \multirow{4}{*}{$\begin{array}{l}\text { New York Hear } \\
\text { Association } \\
\text { Classification }\end{array}$} & Class I & $0 \%$ & $0 \%$ \\
\hline & Class II & $4,0 \%$ & $82,9 \%$ \\
\hline & Class III & $94 \%$ & $17,1 \%$ \\
\hline & Class IV & $2 \%$ & $0 \%$ \\
\hline \multirow{5}{*}{$\begin{array}{l}\text { Etiology of Chronic } \\
\text { Heart Failure }\end{array}$} & Ischemic & $34,6 \%$ & $75,0 \%$ \\
\hline & Hypertensive & $7,7 \%$ & $0 \%$ \\
\hline & Valvular & $7,7 \%$ & $2,3 \%$ \\
\hline & Idiopathic & $46,2 \%$ & $20,5 \%$ \\
\hline & Other & $3,8 \%$ & $2,3 \%$ \\
\hline
\end{tabular}

Fig. 1. Population Characteristics 


\subsection{Instruments and procedure}

Patients were assessed at admission, immediately before the intervention, and in the outpatient clinic within 6 months. We considered functionality by the New York Heart Association classification, left ventricular ejection fraction and the quality of life Kansas City Cardiomyophathy Questionnaire.

The Kansas City Cardiomyopathy Questionnaire (Green et al., 2000) validated for the portuguese population (Nave-Leal et al., 2010) is composed of twenty three items divided into five domains: physical limitation, symptoms, quality of life, self-efficacy and social interference. The physical limitation domain measures the extent to which congestive heart failure symptoms have limited some of the patient's physical activities over the previous two weeks. The symptom domain assesses the number of times that congestive heart failure symptoms such as fatigue, dyspnea or limb edema have occurred in the previous two weeks and whether there have been changes in symptoms during the same period. The self-efficacy domain measures the patient's knowledge of how to avoid worsening of symptoms and of what to do if this occurs. The quality of life domain evaluates patients' perception of their enjoyment of life and of their sense of discouragement due to their heart failure, while the social interference domain assesses how congestive heart failure affects the patient's lifestyle. To facilitate interpretability, two summary scores were developed: the first, the functional status score, combines the physical limitation and symptom domains, and the second, the clinical summary score, combines the functional status score with the quality of life and social interference domains (Figure 2).

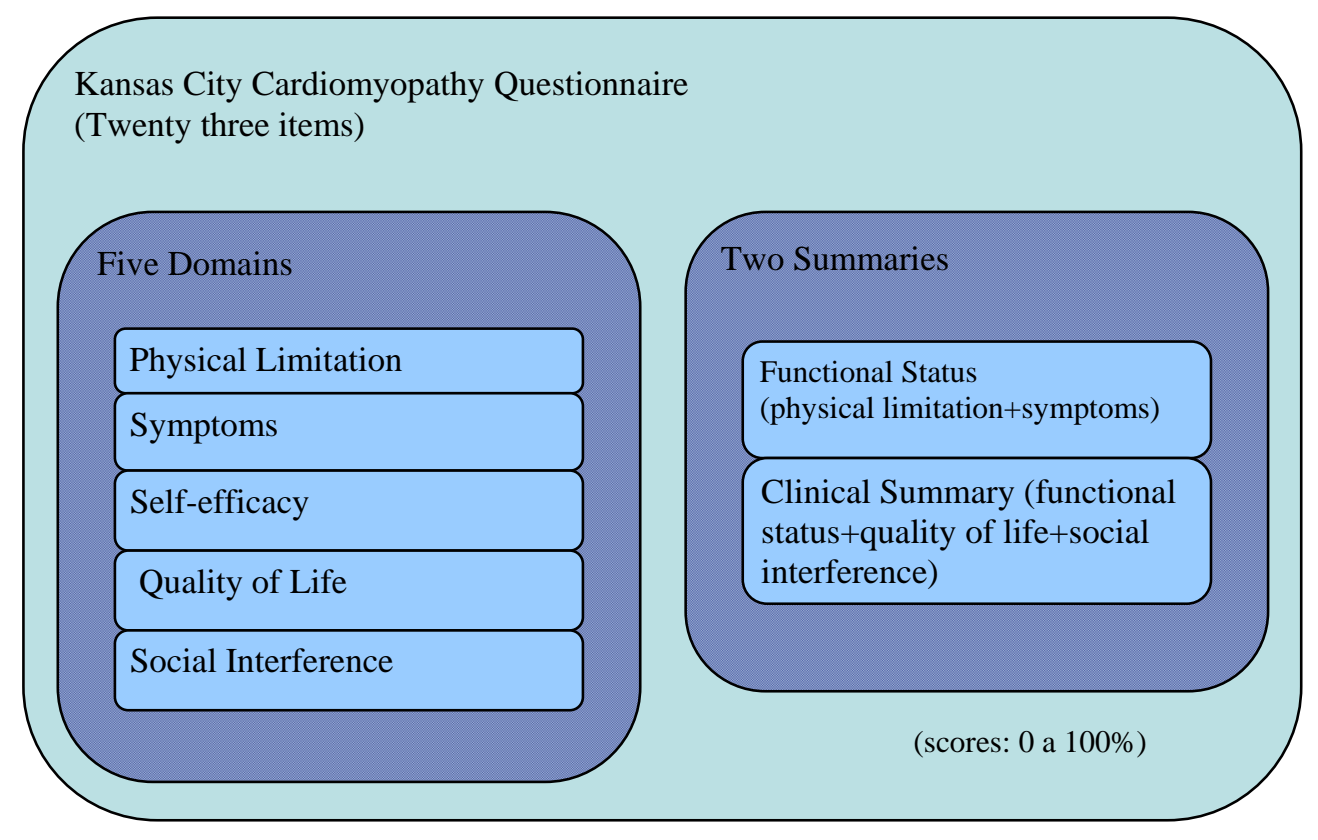

Fig. 2. Domains and Summaries of the Kansas City Cardiomyopathy Questionnaire 
His psychometrics proprieties shows that it's a good instrument regarding fidelity, validity, sensitive to clinical change and specific to measure quality of life in a population with chronic heart failure.

The New York Heart Association classification (The Criteria Committee of the New York Heart Association, 1994 cited by European Society of Cardiology, 2008) measures the functional capacity based on the severity of symptoms and limitation of physical activity and is the most widely used measure to assess functionality of cardiac patients. Class I is defined as the absence of limitations on the exercise usually does not cause fatigue, dyspnoea or palpitations; Class II is characterized by a slight limitation of physical activity, being comfortable at rest but ordinary physical activity causes fatigue, palpitations or dyspnea; Class III is defined by a marked limitation of physical activity, being comfortable at rest but in a less intense activity that usually causes symptoms of heart failure, class IV is characterized by an inability to perform any physical activity without discomfort, where the symptoms of heart failure are present.

The left ventricular ejection fraction calculated by echocardiography in a percentage below $35 \%$ is indicative of poor prognosis.

\section{Results}

During the first six months of follow-up post-implant there was no detection of sustained ventricular tachyarrhythmias.

\subsection{Cardiac resynchronization therapy}

Cardiac resynchronization therapy was associated with improved functionality with New York Heart Association classification, from 3,0 $\pm 0,2$ to 2,1 $\pm 0,5, \rho<0.05$ (Figure 3).

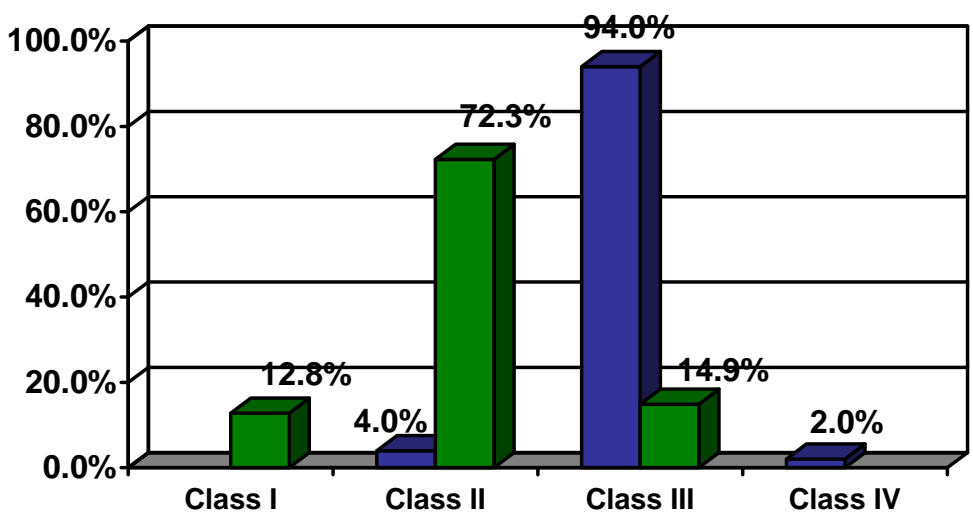

\section{$\square$ Previous $\square$ th Month}

Fig. 3. Functionality at $6^{\text {th }}$ Month Follow-up in Cardiac Resynchronization Therapy

This therapy improved left ventricular ejection fraction, from $24,6 \pm 6,4 \%$ to $35,5 \pm 11,9 \%$, $\rho<0.05$ (Figure 4). 


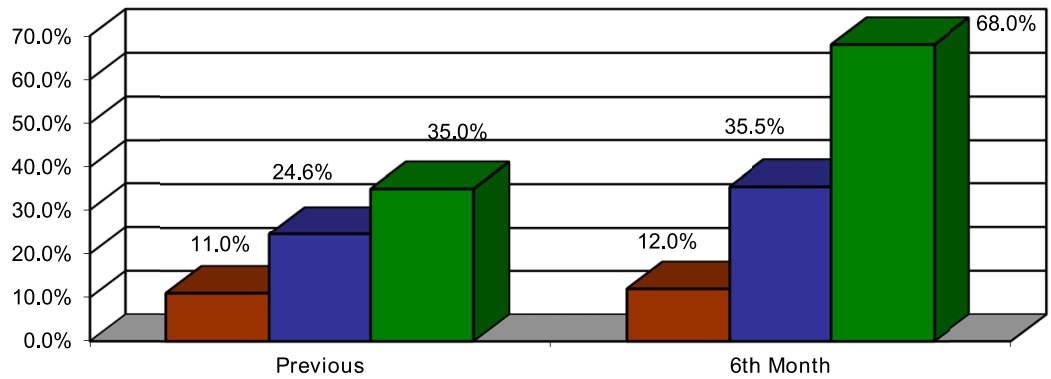

Fig. 4. Left Ventricular Ejection Fraction (LVEF) at $6^{\text {th }}$ Month Follow-up in Cardiac Resynchronization Therapy

Cardiac resynchronization therapy improved quality of life in the various fields and sums assessed except for the self-efficacy domain, high before this therapy (from $81,6 \pm 28,9$ to $88,1 \pm 24,1$, non significant): physical limitation domain from $52,3 \pm 26,7$ to $83,1 \pm 23,6$; symptoms domain from $55,6 \pm 27,6$ to $80,1 \pm 22,3$; quality of life domain from $37,4 \pm 30,1$ to $75,9 \pm 28,6$; social interference domain from $57,8 \pm 30,9$ to $84,6 \pm 25,9$; functional status sum from $55,7 \pm 25,6$ to $82,7 \pm 20,7$ and clinical summary sum from $53,1 \pm 25,7$ to $81,1 \pm 22,1, \rho<0.05$ (Figure 5 ).

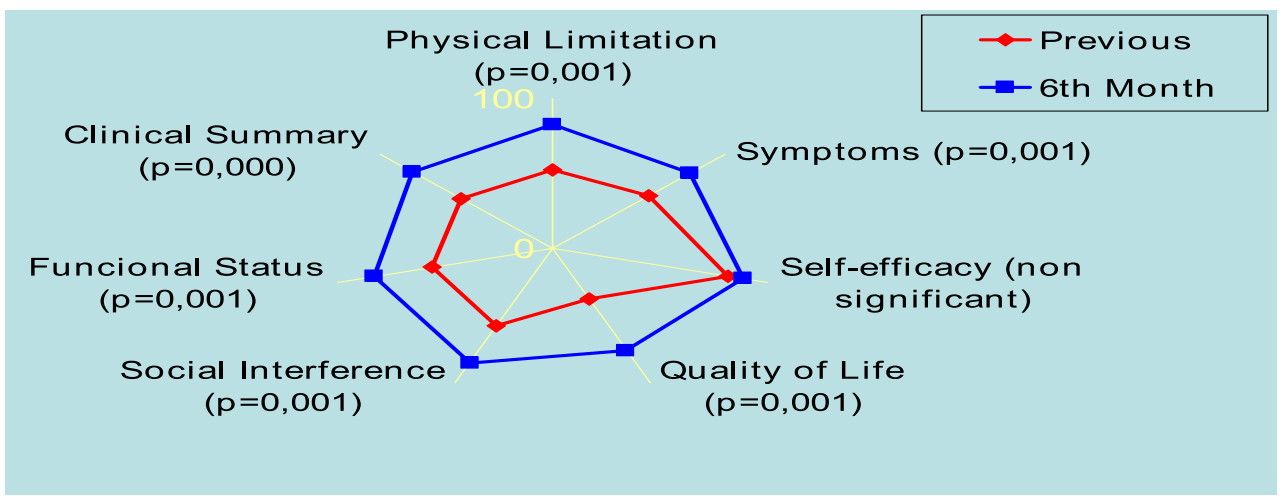

Fig. 5. Quality of Life at $6^{\text {th }}$ Month Follow-up in Cardiac Resynchronization Therapy

We have stratified some of these patients regarding the type of therapeutic response: thirty four patients responded to this therapeutic and nine did not respond to cardiac resynchronization therapy.

Fifteen patients have a left ventricular ejection fraction superior to $45 \%$ post cardiac resynchronization therapy and were classified as super-responders, nineteen patients have a sustained improvement in functional class and an increase in left ventricular ejection fraction of $15 \%$ and were classified as responders and nine patients have no clinical or left ventricular ejection fraction improvement and were classified as non-responders.

The age and the etiology was identical $(65,1 \pm 8,2$ years between $48-75$ years, $63,2 \pm 11,1$ years between $37-78$ and $62,8 \pm 6,1$ years between $55-71$ years for super-responders, responders e non-responders respectively and etiology mainly idiopathic with the majority of the cases 
followed by ischemic etiology according to the results described for the whole group submitted to cardiac resynchronization therapy) but the gender was different with superresponders being in majority women (53,3\% female and $46,7 \%$ male) and responders and non responders being in majority men $(84,2 \%$ male and $15,8 \%$ female and $77,8 \%$ men and $22,2 \%$ female for responders and non-responders respectively).

Super-responders had a left ventricular ejection fraction prior to cardiac resynchronization therapy average superior to $25 \%(29,5 \pm 4,5)$ while responders and non responders presented a left ventricular ejection fraction prior to cardiac resynchronization therapy average inferior to $25 \%(22,6 \pm 6,2$ and $23,9 \pm 6,5)$ (Figure 6).



Fig. 6. Left Ventricular Ejection Fraction Regarding the Type of Therapeutic Response

Super responders and responder had the all of their patients in class III of the New York Heart Association classification prior to therapy while non-responders despite having the majority of the patients in class III $(66,7 \%)$ also had patients in class II $(22,2 \%)$ and class IV $(11,1 \%)$ of the New York Heart Association classification prior to therapy (Figure 7).

Non responders presented a low quality of life before this therapy and have not perceived any improvement on their quality of life (physical limitation domain from $25,2 \pm 21,9$ to $59,1 \pm 37,4$; symptoms domain from $46,5 \pm 33,3$ to $63,6 \pm 28,2$; self-efficacy domain from $95,8 \pm 7,3$ to $97,59 \pm 7,1$; quality of life domain from $20,8 \pm 27,4$ to $52,1 \pm 35,1$; social interference domain from $37,5 \pm 31,5$ to $63,8 \pm 36,8$; functional status sum from $38,1 \pm 28,9$ to $63,8 \pm 30,4$ and clinical summary sum from $34,8 \pm 28,4$ to $60,1 \pm 32,2$ ) (Figure 8 ).

Super-responders and responders started with a better perception of their quality of life and identify improvement in quality of life in all dimensions and sums, $p \leq 0,05$ except for the auto-efficacy dimension in responders where there was no statistical significant change (physical limitation domain from $51,8 \pm 24,6$ to $90,4,1 \pm 13,7$; symptoms domain from $53,9 \pm 27,6$ to $84,5 \pm 21,8$; self-efficacy domain from $76,2 \pm 34,3$ to $95,7 \pm 11,6$; quality of life domain from $38,7 \pm 31,6$ to $85,1 \pm 24,5$; social interference domain from $55,8 \pm 27,1$ to $85,7 \pm 28,9$; functional status sum from $55,3 \pm 22,6$ to $87,7 \pm 17,4$ and clinical summary sum from $52,6 \pm 23,4$ to 
$60,1 \pm 32,2$ for super responders and physical limitation domain from $63,1 \pm 23,7$ to $89,1 \pm 15,3$; symptoms domain from $60,1 \pm 25,7$ to $82,4 \pm 20,9$; self-efficacy domain from $76,9 \pm 33,1$ to $83,3 \pm 26,8$; quality of life domain from $39,8 \pm 27,4$ to $75,1 \pm 27,6$; social interference domain from $63,9 \pm 31,7$ to $90,2 \pm 18,3$; functional status sum from $62,6 \pm 23,8$ to $86,6 \pm 15,7$ and clinical summary sum from $59,2 \pm 23,7$ to $84,9 \pm 17,8$ for responders) (Figure 9 and Figure 10).

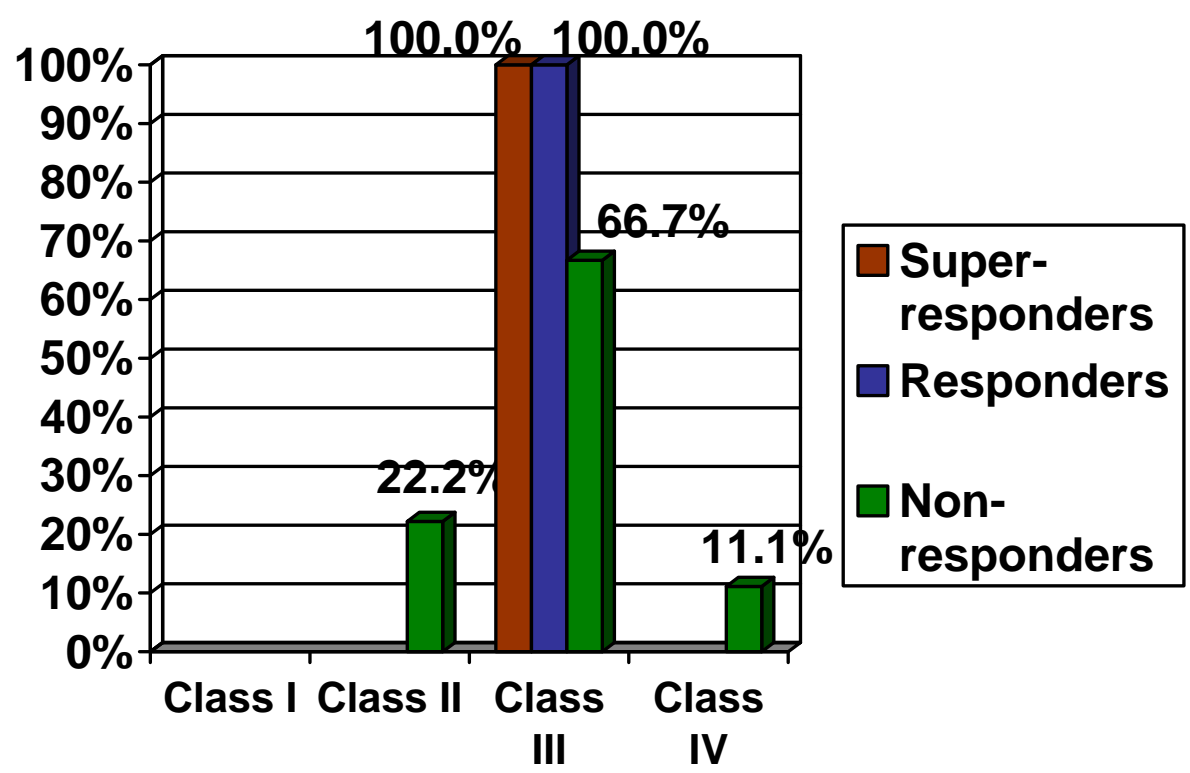

Fig. 7. New York Heart Association Classification Regarding the Type of Therapeutic Response

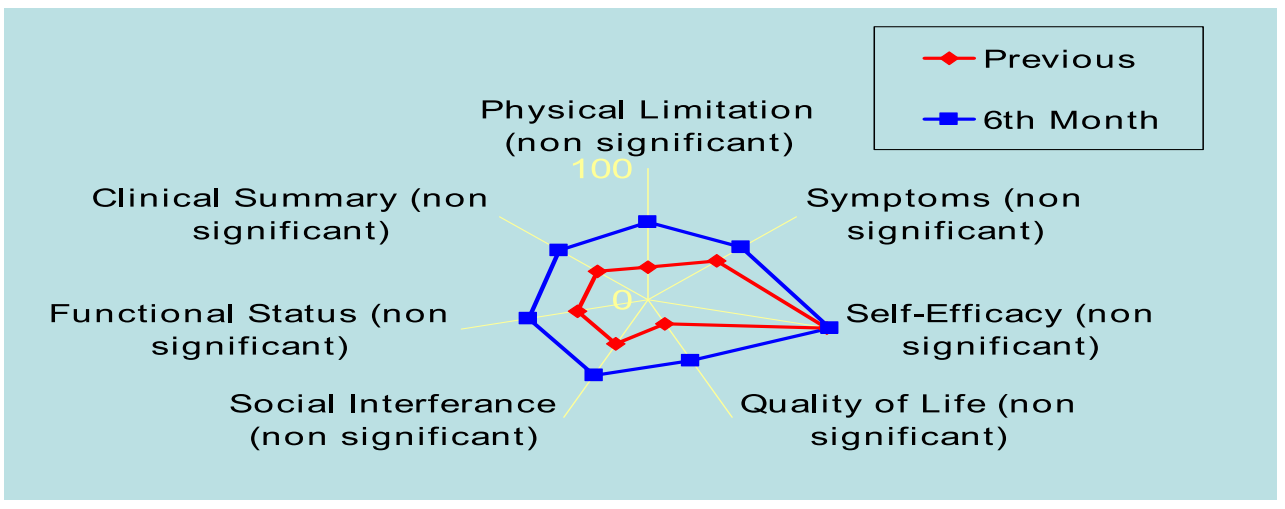

Fig. 8. Quality of Life in Non-responders 


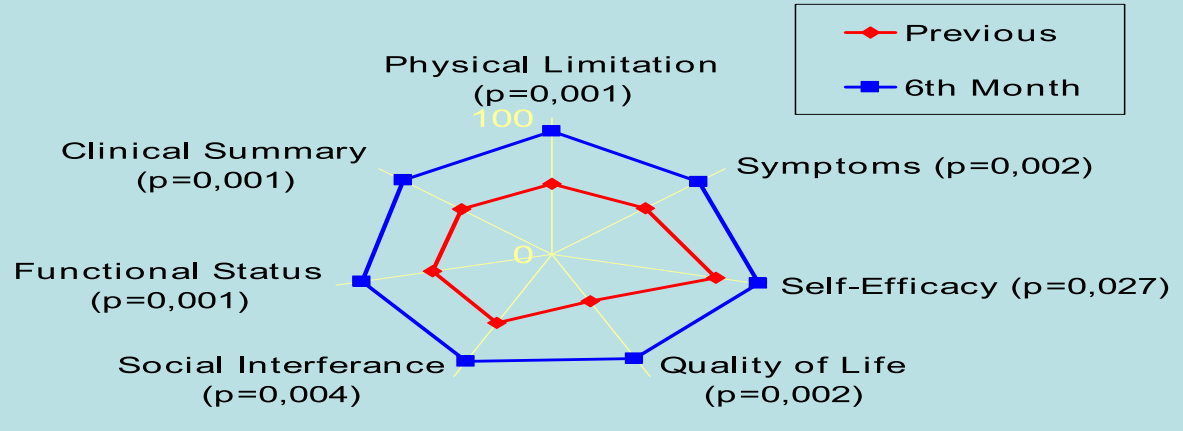

Fig. 9. Quality of Life in Super-responders

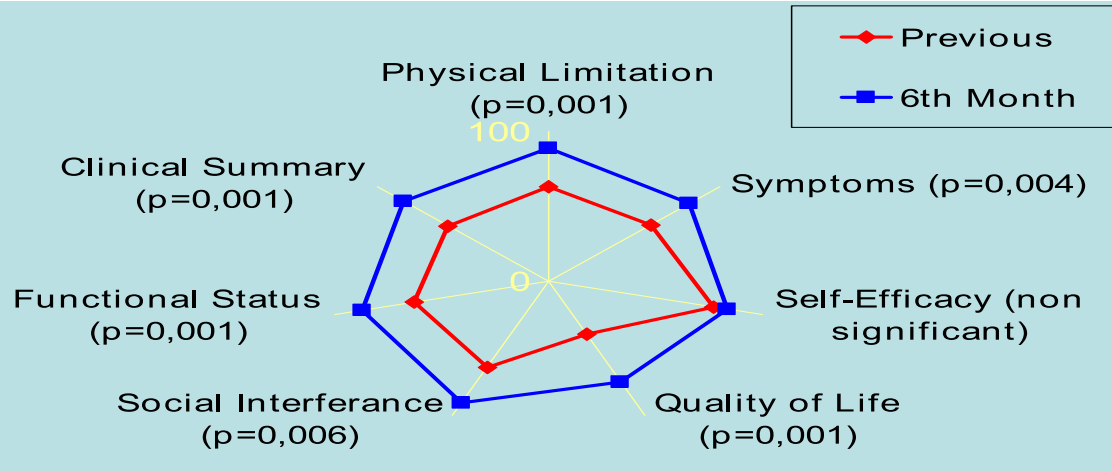

Fig. 10. Quality of Life in Responders

\subsection{Implantable cardioverter-defibrillator}

Implantable cardioverter defibrillator was associated with improved functionality with New York Heart Association classification from 2,1 $\pm 0,3$ to 1,9 $90,5 \rho<0.05$ (Figure 11).

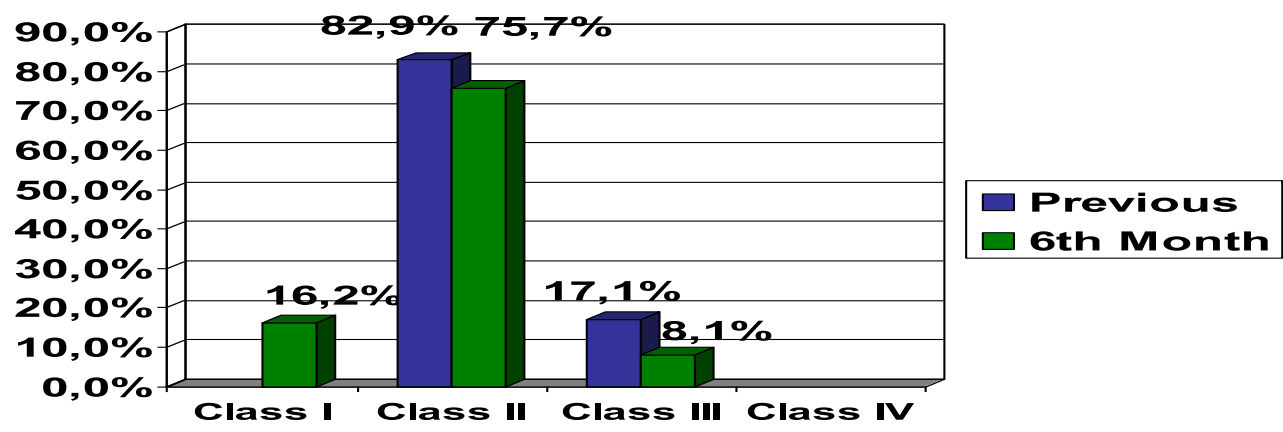

Fig. 11. Functionality at $6^{\text {th }}$ Month Follow-up in Implantable Cardioverter Defibrillator 
This device was not associated with improvement in left ventricular ejection fraction (from $26,1 \pm 5,4$ to $26,4 \pm 5,9$ ), where changes were no significant (Figure 12).

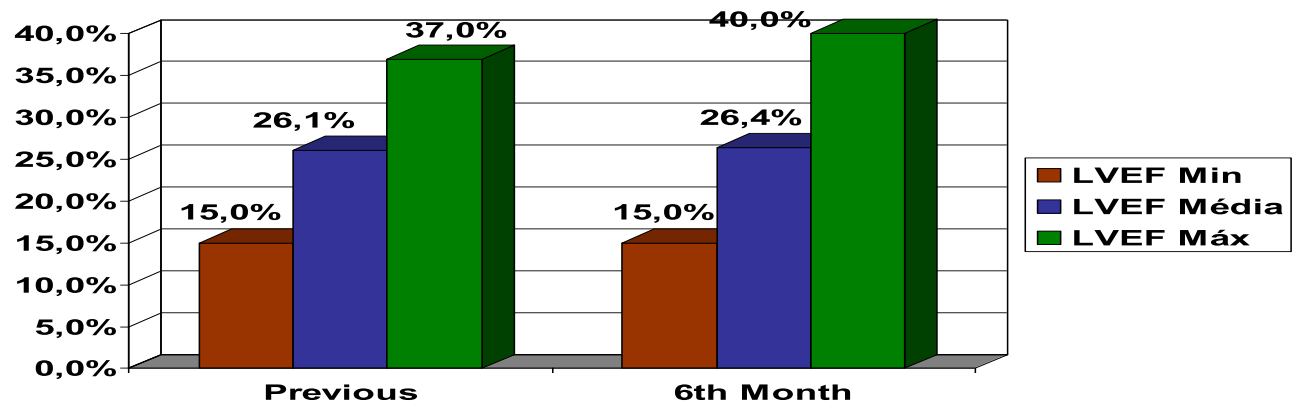

Fig. 12. Left Ventricular Ejection Fraction (LVEF) at $6^{\text {th }}$ Month Follow-up in Implantable Cardioverter Defibrillator

Implantable cardioverter-defibrillator improved quality of life only in social interference domain from $73,9 \pm 34,4$ to $82,7 \pm 27,5$, quality of life domain from $54,3 \pm 32,1$ to $71,1 \pm 28,1$ and clinical summary sum from $72,4 \pm 24,1$ to $78,4 \pm 25,1, \rho<0.05$. In the physical limitation domain (from $76,2 \pm 24,5$ to $80,4 \pm 26,1$ ), symptoms domain (from $73,6 \pm 24,7$ to $78,1 \pm 24,6$ ), self-efficacy domain (from $80,3 \pm 26,2$ to $83,6 \pm 25,1$ ) and functional status sum (from $76,2 \pm 23,1$ to $80,4 \pm 23,9)$, changes were no significant (Figure 13). Initial scores in every dimension and sum were high before the implantation of this device.

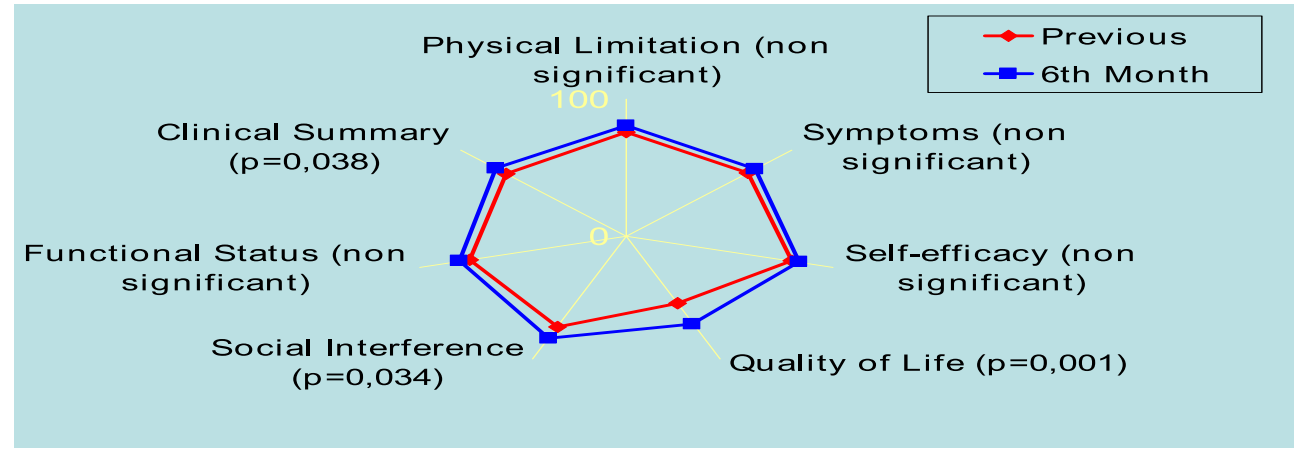

Fig. 13. Quality of Life at $6^{\text {th }}$ Month Follow-up in Implantable Cardioverter Defibrillator

\section{Discussion}

In this study the cardiac resynchronization therapy combined with implantable cardioverter-defibrillator improved left ventricular function, functionality and quality of life at six months follow-up. According to the European Cardiac Society, 2008 the survival advantage of cardiac resynchronization therapy with implantable cardioverter-defibrillator has not been adequately addressed. However due to the documented effectiveness of 
implantable cardioverter-defibrillator therapy in the prevention of sudden cardiac death, the use of cardiac resynchronization therapy associated to implantable cardioverter-defibrillator is commonly preferred in clinical practice in patients satisfying cardiac resynchronization therapy criteria including an expectation of survival with good functional status for more than one year. Lousano et al., 2005 in the VENTAK CHF/CONTAK CD study followed 490 heart failure patients with indication for an implantable cardioverter-defibrillator compared antitachycardia pacing efficacy in patients with or without cardiac resynchronization therapy. These authors encountered that the efficacy of biventricular antitachycardia pacing in heart failure patients is significantly better in those with cardiac resynchronization therapy than in those without.

Other studies have identified the benefits of this therapy in mortality and morbidity of patients with heart failure. Bristow et al., 2004 in the COMPANION study analysed the effect of the cardiac resynchronization therapy in mortality and hospitalization among patients with advanced chronic heart failure and intraventricular conduction delays. 1520 patients in New York Heart Association class III or IV due to ischemic or nonischemic cardiomyopathies and a QRS interval of at least $120 \mathrm{~ms}$ were randomly assigned in three groups to receive optimal pharmacologic therapy (diuretics, angiotensin-converting-enzyme inhibitors, beta-blockers and spironolactone) alone or in combination with cardiac resynchronization therapy with either a pacemaker or a pacemaker-defibrillator. These authors encountered that cardiac resynchronization therapy decreases the combined risk of death from any cause or first hospitalization and, when combined with an implantable defibrillator, significantly reduces mortality. Cleland et al., 2005 in the CARE-HF study analyzed the effects of cardiac resynchronization therapy on morbidity and mortality among patients with heart failure due to left ventricular systolic dysfunction and cardiac dyssynchrony. 813 patients with New York Heart Association class III or IV heart failure due to left ventricular systolic dysfunction and cardiac dyssynchrony who were receiving standard pharmacologic therapy were randomly assigned to receive medical therapy alone or with cardiac resynchronization. These authors encountered that cardiac resynchronization increases left ventricular ejection fraction, improve symptoms and the quality of life and reduce complications and the risk of death. McAlister et al., 2007 in a systematic review concerning the efficacy, effectiveness and safety of cardiac resynchronization therapy in patients with left ventricular systolic dysfunction in a total of 14 randomized trials involving 4420 patients, observed that cardiac resynchronization therapy improved left ventricular ejection fraction, quality of life and functionality and decreased hospitalizations and all cause mortality with a high implant rate and low lead problems during eleven months follow-up. They conclude that this therapy reduces morbidity and mortality in patients with left ventricular systolic dysfunction, prolonged QRS duration and New York Heart Association class III and IV symptoms when combined with optimal pharmacotherapy. About the sustained effect of this therapy Sutton et al., 2006 in the MIRACLE study followed 228 patients submitted to cardiac resynchronization therapy during twelve months post-implantation to determine whether reverse left ventricular remodeling and symptomatic benefit from this therapy were sustained at one year and if so, in what proportion. These authors encountered that reverse left ventricular remodeling and symptom benefit are sustained at twelve months in patients with New York Heart Association class III/IV heart failure but occur to a lesser degree 
in patients with ischemic versus non-ischemic etiology, according to them most likely owing to the inexorable progression of ischemic disease.

Despite the good results achieved with cardiac resynchronization therapy according to Santos et al., 2006 one third of the patients do not benefit from it. In our study, from forty-three patients, eight did not respond to this therapy. This group identified a low quality of live before implantation and did not perceive any improvement after cardiac resynchronization therapy. Also in this non-responding group we had patients in class II to IV of the New York Heart Association classification before intervention. Interestingly the super-responders were majority women and have a left ventricular ejection fraction prior to implantation superior to $25 \%$. The response to this therapy was associated to improvement of quality of life perceived by the patients and a New York Heart Association class III classification before implantation. There are few studies regarding the predictors of response to this therapy. Quiao et al., 2011 in a study with seventy-six consecutive patients submitted to cardiac resynchronization therapy divided in to superresponders, responders and non-responders conclude that patients with a smaller left ventricle would have a better chance to become super-responders. Santos et al., 2006 in twenty-three consecutive patients with heart failure refractory to medical therapy who underwent cardiac resynchronization therapy studied regarding the type of response before and six months after the procedure evaluating clinical, electrocardiographic and echocardiography characteristics concluded that left ventricular dyssynchrony can be quantified by tissue Doppler imaging using QS (max-min) and values greater than $60 \mathrm{~ms}$ can identify responders to this therapy. This actual field under investigation requires more studies to determine the reasons for a percentage of these patients do not respond to cardiac resynchronization therapy including personal characteristics of the patients.

In this study implantable cardioverter-defibrillator alone was associated with improvement of functionality and quality of life already high in baseline due to the majority of the patients being in class II of the New York Heart Association classification. When looking to the various dimensions concerning the quality of life we stated that this improvement is observed in social and quality of life domains with this patients referring improvement of the perception of their enjoyment of life and of their sense of discouragement due to their heart failure and how congestive heart failure affects the patient's lifestyle at six month follow-up, emphasizing the necessity of looking to all dimensions evaluated in quality of life and not only the overall score to characterize the evolution of patients to clinical interventions. It is known the effect of this device on improving survival, however remains unclear the effect of this treatment in quality of life. Bardy et al., 2005 in the SCD-HeFT study concerning the effect of amiodarone or a conservatively programmed, shock-only implantable cardioverter-defibrillator in reducing the risk of death in patients with mild-to-moderate congestive heart failure, followed 2521 patients in class II or III with chronic stable heart failure due to ischemic or non-ischemic causes and left ventricular ejection fraction $\leq 35 \%$ randomized for receiving amiodarone, implantable cardioverter-defibrillator or placebo. These authors encountered that in patients with mild-to-moderate congestive heart failure, conservatively programmed, shock-only implantable cardioverter-defibrillator significantly reduces risk of death while amiodarone shown no benefit compared with placebo; implantable cardioverter-defibrillator therapy had significant benefit in patients with New York Heart 
Association class II but no significant effect in patients with class III; amiodarone had no benefit in patients with New York Heart Association class II and showed a significant reduction in survival in patients with class III compared to placebo. Noyes et al., 2009 in the MADIT-II study followed 938 patients randomized to receive an implantable cardioverter-defibrillator or medical therapy alone during thirty six months. These authors encountered that development of congestive heart failure and shocks among patients and their negative effect on quality of life may partially explain the lack of quality of life benefit from this therapy. Probst et al., 2011 have studied the psychological impact of implantable cardioverter-defibrillator on Brugada syndrome patients. 190 patients were divided in three groups: symptomatic implanted patients, asymptomatic implanted patients and asymptomatic patients without implantable cardioverter-defibrillator and were evaluated regarding the quality of life. These authors concluded that whatever the group, Brugada patients have a good quality of life with no difference between implanted and non-implanted patients. Despites the difficulties in their social and professional life regarding the tolerance of this device, patients considered implantation of cardioverterdefibrillator reassuring.

\section{Conclusion}

In a selected population with severe chronic heart failure, cardiac resynchronization therapy was associated with improvement in all domains of quality of life, functional class and left ventricular function. Regarding the type of response to this therapy, patients with positive clinical response and reverse remodeling, obtained a favorable impact in all dimensions of quality of life, while the group without response showed no improvement, with some differences between the responding and the non-responding patients like gender, perceived quality of life and the New York Heart association classification prior to implantation of the device that needs further investigation.

Implantable cardioverter-defibrillator benefits were restricted to the social dimension of quality of life and perception of life satisfaction, indicating that this intervention as no unfavorable impact in quality of life in the first six months after the implantation of this device in patients without detection of sustained ventricular tachyarrhythmias

\section{Acknowledgements}

The authors are grateful to the following bodies and staff of Hospital de Santa Marta: the Administrative Board; the Ethics Committee; cardiologists and cardiopneumologists of the arrhythmology clinic; and cardiologists of the heart failure clinic.

\section{References}

Bardy, G., Lee, K., Mark, D., Poole, J., Packer, D., Boineau, R., Domansky, M., Troutman, C., Anderson, J., Johnson, G., McNulty, S., Clapp-Channing, N., Davidson-Ray, L., Fraulo, E., Fishbein, D., Luceri, R., \& Ip, J. (2005). Amiodarone or an implantable cardioverter-defibrillator for congestive heart failure.The New England Journal of Medicine, Vol.352,pp. 225-237 
Bristow, M., Saxon, L., Boehmer, J., Krueger, S., Kass, D., De Marco, T., Carson, P., DiCarlo, L., DeMets, D., White, B., DeVries, D., \& Feldman, A. (2004). CardiacResynchronization Therapy with or without an Implantable Defibrillator in Advanced Chronic Heart Failure. The New England Journal of Medicine, Vol.350, No.21 (May 2004),pp. 2140-2150

Cleland, J., Daubert, J., Erdmam, E., Fremantle, N., Gras, D., Kappenberger, L., \& Tavazzi, L. (2005). The Effect of Cardiac Resynchronization on Morbidity and Mortality in Heart Failure. The New England Journal of Medicine, Vol.325, No.15 (April 2005),pp. 1539-1549

European Society of Cardiology (2008). ESC Guidelines for the diagnosis and treatment of acute and chronic heart failure 2008. European Heart Journal, vol. 29,pp. 23882442

Green, C., Porter, C., Bresnahan, D., \& Spertus, J. (2000) Development and Evaluation of the Kansas City Cardiomyopathy Questionnaire: A New Health Status Measure for Heart Failure. Journal of the American College of Cardiology, Vol.35, No.5,pp. 12451255

Lousano, I., Higgins, S., Villa, J., Niazi, I., Toquero, J., Yong, P., Madrid, A., \& Pulpón, L. (2005) Antitachycardia Pacing Efficacy Significantly Improves With Cardiac Resynchronization Therapy. Revista Espanhola de Cardiology, Vol.58, No.10,pp. 11481154

McAlister, F., Ezekowitz, J., Hooton, N., Vandermeer, B., Spooner, C., Dryden, D., Page, R., Hlatky, M., \& Rowe, B. (2007). Cardiac Resynchronization Therapy for Patients with Left Ventricular Systolic Dysfunction: A Systematic Review. Journal of the American Medical Association, Vol.297, No.22,pp. 2502-2514

Nave-Leal, E., Pais-Ribeiro, J., Oliveira, M., Nogueira da Silva, J. Soares, R, Fragata, J. \& Ferreira, R. (2010). Psychometric Properties of the Portuguese Version of the Kansas City Cardiomyopathy Questionnaire in Dilated Cardiomyopathy with Congestive Heart Failure. Revista Portuguesa de Cardiologia, Vol.29, No.3,pp. 353-372

Noyes, K., Corona, E., Veazie, P., Dick, A., Zhao, H., \& Moss, A. (2009). Examination of the Effect of Implantable Cardioverter-Defibrillators on Health Related Quality of Life: Based on Results from the Multicenter Automatic Defibrillator Trial-II. American Journal of Cardiovascular Drugs, Vol.9, No.6,pp. 393-400

Probst, V., Plassard-Kerdon-Cuf, D., Mansourati, J., Mabo, P., Sacher, F., Fruchet, C., Babuty, D., Lande, G., Guyomarc'h, B., \& Le Marec, H. (2011). The Psychological Impact of Implantable Cardioverter Defibrillator Implantation on Brugada Syndrome Patients. Europace, Vol.13, No.7,pp. 1034-1039

Quiao, Q., Ding, L., Hua, W., Chen, K., Wang, F., \& Zhang, S. (2011). Potencial Predictors of Non-response to Cardiac Resynchronization Therapy. Chinese Medical Journal, Vol.124, No.9 (May 2011),pp. 1338-1441

Santos, J., Parreira, L., Madeira, J., Seixo, F., Mendes, L., Lopes, C., Venâncio, J., Lourenço, J., Caetano, F., Inês, L., \& Mendes, M. (2006). Predictors of Response to Cardiac Resynchronization Therapy: Importance of Left Ventricular 
Dyssynchrony. Revista Portuguesa de Cardiologia, Vol.25, No.6 (June 2006),pp. 569-581

Sutton, M., Plappert, T., Hilpisch, B., Abraham, W., Hayes, D., \& Chinchoy, E. (2006). Sustained Reverse Left Ventricular Structural Remodling with Cardiac Resynchronization at One Year in Function of Etiology. Circulation, Vol.113,pp. 266272 


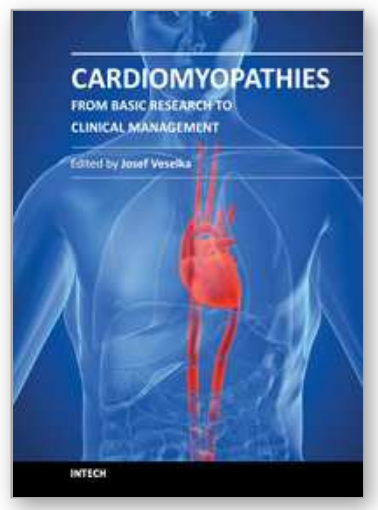

\author{
Cardiomyopathies - From Basic Research to Clinical Management \\ Edited by Prof. Josef Veselka
}

ISBN 978-953-307-834-2

Hard cover, 800 pages

Publisher InTech

Published online 15, February, 2012

Published in print edition February, 2012

Cardiomyopathy means "heart (cardio) muscle (myo) disease (pathy)". Currently, cardiomyopathies are defined as myocardial disorders in which the heart muscle is structurally and/or functionally abnormal in the absence of a coronary artery disease, hypertension, valvular heart disease or congenital heart disease sufficient to cause the observed myocardial abnormalities. This book provides a comprehensive, state-of-theart review of the current knowledge of cardiomyopathies. Instead of following the classic interdisciplinary division, the entire cardiovascular system is presented as a functional unity, and the contributors explore pathophysiological mechanisms from different perspectives, including genetics, molecular biology, electrophysiology, invasive and non-invasive cardiology, imaging methods and surgery. In order to provide a balanced medical view, this book was edited by a clinical cardiologist.

\title{
How to reference
}

In order to correctly reference this scholarly work, feel free to copy and paste the following:

Elisabete Nave Leal, José Luís Pais Ribeiro and Mário Martins Oliveira (2012). Quality of Life in Dilated Cardiomyopathy with Refractory Chronic Heart Failure Undergoing Devices Implantation, Cardiomyopathies From Basic Research to Clinical Management, Prof. Josef Veselka (Ed.), ISBN: 978-953-307-834-2, InTech, Available from: http://www.intechopen.com/books/cardiomyopathies-from-basic-research-to-clinicalmanagement/quality-of-life-in-dilated-cardiomyopathy-with-refractory-chronic-heart-failure-undergoingdevices-i

\section{INTECH}

open science | open minds

\section{InTech Europe}

University Campus STeP Ri

Slavka Krautzeka 83/A

51000 Rijeka, Croatia

Phone: +385 (51) 770447

Fax: +385 (51) 686166

www.intechopen.com

\section{InTech China}

Unit 405, Office Block, Hotel Equatorial Shanghai

No.65, Yan An Road (West), Shanghai, 200040, China

中国上海市延安西路65号上海国际贵都大饭店办公楼405单元

Phone: +86-21-62489820

Fax: $+86-21-62489821$ 
(C) 2012 The Author(s). Licensee IntechOpen. This is an open access article distributed under the terms of the Creative Commons Attribution 3.0 License, which permits unrestricted use, distribution, and reproduction in any medium, provided the original work is properly cited. 